\title{
LASER HARDENING PROCESS OPTIMIZATION USING FEM
}

\author{
Andris Martinovs ${ }^{1}$, Svetlana Polukoshko ${ }^{2}$, Edgars Zaicevs ${ }^{1}$, Ritvars Revalds ${ }^{1}$ \\ ${ }^{1}$ Rezekne Academy of Technologies, Latvia; ${ }^{2}$ Ventspils University of Applied Sciences, Latvia \\ andris.martinovs@ru.lv, pol.svet_a@inbox.lv, edgars.zaicevs@rta.lv, ritvars.revalds@ rta.lv
}

\begin{abstract}
In given work a method for optimization of the process of laser hardening of steel parts is developed. The approach is based on the finite element method (FEM) using computer program "COMSOL Multiphysics" (module Heat Transfer in Solids) - software for multi-physical processes simulation. This method allows to reduce the number of laser hardening experiments, replacing them with numerical calculations, and to find the optimal parameters of the used laser equipment. To perform the calculations it is necessary to know the hardening temperature range of the particular steel grade, the martensite formation start temperature, the critical value of the cooling rate, the material density, the thermal conductivity $k=k(T)$, the specific heat capacity $C_{p}=C_{p}(T)$ and the surface reflectivity $R=R(T, \lambda)$, where $T$ temperature, $\lambda$ - wavelength of laser beam. Depending on the laser power, the feed rates of the laser beam, the spot size and the distribution of energy in it, the temperature field is calculated for the steel part in different moments of time. Analysing these data it is possible to determine the thickness of the hardened layer or to predict damage to the material of a given steel part due to heat treatment. The method has been tested experimentally.
\end{abstract}

Keywords: C45 steel, laser hardening, FEM, process optimization.

\section{Introduction}

In the process of manufacturing of machine parts it is common to use the induction or muffle furnaces for steel parts hardening. These furnaces require a significant amount of electrical energy to operate. In the industry for machine parts C45 steel is widely used, but this material has a disadvantage in the hardening process - during cooling of the steel part in water cracking is observed. In order to make the hardening process of steel parts more safe (to reduce cracking during cooling) and more energy efficient laser radiation can be used as an energy source. Its advantages are:

1. material properties do not change in other places of parts, because only the area that needs to be hardened is heated;

2. the possibility of crack occurring during cooling is reduced, since only a small part of the volume of the part is heated; the remaining volume of the material serves as an efficient coolant providing the cooling rate required for the hardening process; no liquid medium is needed for cooling, it can be done in air;

3. it is possible to dose the supplied energy and, depending on it, change the heating temperature, hardened layer thickness and hardness.

In connection with the introduction of the laser hardening process, several studies have been carried out. For example, in [1], the authors discuss the modernization of a 5-axis milling machine by introducing laser hardening equipment based on a $500 \mathrm{~W}$ Nd: Yag laser and a laser head mounted on the machine spindle.

The effect of radiation on the material is determined by the laser parameters, process parameters and the properties of the processed material. Laser characteristics include the power, wavelength, pulse frequency, pulse width, etc. The process parameters are the scanning speed, spotsize, number of scans, defocusing distance, radiation energy density, cooling rate of part, etc. Parameters characterizing the material properties are the chemical composition, quenching temperature range, martensite start temperature, density, thermal conductivity, specific heat capacity, reflection coefficient, absorption coefficient, emissivity, etc. Numerically measurable results of hardening are hardness, thickness of hardened layer, percentage of martensite structure in hardened material. The thickness of the hardened layer of the parts used in machinery engineering is usually in the range of 0.7 to $2.5 \mathrm{~mm}$ with a hardness of 55 to $61 \mathrm{HRC}$.

If the laser radiation energy is too high, the area of the downward radiation may be melted or burned by ablation. In this case, the dimensions of the machine parts will be out of tolerance and the obtained defect is not permissible. The cooling rate required for hardening is achieved by transferring heat to areas of the steel part that are not subject to laser exposure. In this case, the greater the mass of the component, the more efficient the heat removal process from the laser treatment area. The laser 
hardening process depends on many of the above factors. This means that optimization of the given process is required. Optimization requires a large number of experiments [1]. The number of real experiments may be reduced by replacing them with numerical experiments based on an appropriate mathematical model and FEM to solve it. For example, in paper [2], a mathematical model of the laser annealing process for rotating cylindrical components of AISI 4340 steel was developed to predict temperature distribution and hardened layer thickness using FDM (finite difference method). Authors of work [1] investigated the laser hardening process of C45 steel using the Nd: Yag laser (maximum power $450 \mathrm{~W}$, wavelength $1064 \mathrm{~nm}$, scan speed $100-400 \mathrm{~mm} \cdot \mathrm{min}^{-1}$, spotsize diameter $2.60-2.78 \mathrm{~mm}$ ) and developed the mathematical modelling of this process using FEM. Optimization of the laser cutting process for steel is discussed in [3].

For $\mathrm{C} 45$ steel laser welding process optimization the calculation of temperature fields is studied in [4], which allows replacing of real experiments by numerical calculations. There are other (non FEM based) laser processing optimization methods; for example, the authors of [5] have developed an efficient method for optimizing the laser marking process based on genetic algorithms. The method is applicable, when the parameters characterizing the laser treatment of the material result are easy to measure or determine, because it requires a large amount of experimental results. Unfortunately, for optimization of the hardening process this method is difficult to use, because it takes a significant amount of time to obtain one experimental result (measuring the hardening depth). In this case it is more advantageous to use FEM calculations of temperature fields for process optimization.

The objective of this work is to develop a method for optimizing the laser hardening process of steel parts using FEM numerical calculations. The parameters to be optimized are the laser power, scanning speed and the spot diameter in order to ensure hardening of the C45 steel surface ( $\geq 55 \mathrm{HRC}$ or $649 \mathrm{HV}$ ) to a depth of at least $0.9 \mathrm{~mm}$.

\section{Materials and methods}

The material under investigation is $\mathrm{C} 45$ steel. The chemical composition (\% by mass) of steel according to EN 10083 / 2-2006 [6] and the supplier's certificate are given in Table 1.

Table 1

\section{Chemical composition of $\mathrm{C} 45$ steel}

\begin{tabular}{|c|c|c|c|c|c|c|c|c|c|c|c|c|}
\hline Material & C & Mn & P & S & Si & Cr & Mo & Ni & Al & Cu & Sn & Cr+Mo+Ni \\
\hline $\begin{array}{c}\text { EN 10083/ } \\
\text { 2-2006 }\end{array}$ & 0.42 & 0.50 & Max & Max & Max & Max & Max & Max & - & - & - & $\begin{array}{c}\text { Max } \\
0.80\end{array}$ \\
0.045 & 0.045 & 0.40 & 0.40 & 0.10 & 0.40 & - & - & & 0.63 \\
\hline $\begin{array}{c}\text { Supplier } \\
\text { Certificate }\end{array}$ & 0.46 & 0.58 & 0.014 & 0.026 & 0.25 & 0.15 & 0.03 & 0.09 & 0.025 & 0.18 & 0.014 & 0.27 \\
\hline
\end{tabular}

For hardening experiments a diode laser $(808 \mathrm{~nm}$ and $940 \mathrm{~nm})$ is used. The laser operates in CW mode. For hardening tests, a workpiece for automobile gear manufacturing is used (see Fig. 7); it is a C45 steel component with a diameter of $300 \mathrm{~mm}$ and a thickness of $10-12 \mathrm{~mm}$. The material is not initially hardened and has a hardness of 240-260 HV (21-26 HRC). The component has flat surfaces on which laser tempering tests are performed. The focused laser beam moves along the flat surface of a given part. The laser beam trajectory is a straight line of $30 \mathrm{~mm}$ length, which is the scanning length; number of scans -1 . The laser beam power $(300-1500 \mathrm{~W})$, scan speed $\left(3-10 \mathrm{~mm} \cdot \mathrm{s}^{-1}\right)$ and the spot diameter $(3-5 \mathrm{~mm})$ are changing during the tests. The distance between the test areas on a flat surface should be at least $30 \mathrm{~mm}$. The unit is cooled in dead air at $20^{\circ} \mathrm{C}$.

After laser heat treatment each testing area (where there is no visible surface damage due to laser radiation) is cut out of the part so as to obtain a section, perpendicular to the hardened surface of the part. This slit is polished and etched (4\% HNO3 in ethanol). The Olympus LEXT OLS5000 3D Measuring Laser Microscope provides a sectional metallographic image to determine the existence of a martensite structure. By measuring the hardness ( $\mathrm{HV}$, load $1 \mathrm{~kg}$ ) of this slit, the thickness of the hardened layer is determined.

For numerical experiments a multi-physical modelling program COMSOL 5.4 is used; Physical Model: Heat Transfer in Solids; Study Type: Time Dependent, Space Dimension: 3D. Laser hardening 
of steel is described as a non-stationary heat transfer process in a homogeneous, isotropic material using the equation $[2 ; 7-9]$ :

$$
\rho \cdot C_{p} \cdot \frac{\partial T}{\partial t}-k \cdot\left(\frac{\partial^{2} T}{\partial x^{2}}+\frac{\partial^{2} T}{\partial y^{2}}+\frac{\partial^{2} T}{\partial z^{2}}\right)=q_{V}
$$

where $\rho$-density, $\mathrm{kg} \cdot \mathrm{m}^{-3}$;

$C_{p}=C_{p}(T)$ - specific heat capacity at constant pressure, $\mathrm{J} \mathrm{kg}^{-1} \cdot \mathrm{K}^{-1}$;

$T$ - absolute temperature, K;

$t$ - time, $\mathrm{s}$;

$k=k(T)-$ thermal conductivity, $\mathrm{W} \cdot \mathrm{m}^{-1} \cdot \mathrm{K}^{-1}$;

$q_{V}$ - capacity of internal heat sources per unit volume, $\mathrm{W} \cdot \mathrm{m}^{-3}$.

If the material is not translucent to laser radiation (e.g. steel in UV, visible or near IR radiation), $q_{V}=0$. If the material is transparent to laser radiation, the absorption of radiation occurs in the volume of the material, and the Beer-Lambert-Bouguer law must be taken into account in the calculation of qv. The surface of the material on which the laser beam falls is heated. Cooling of the heated topcoat at the rate required for steel hardening is provided by heat transfer to the internal non-heated areas. Atomic and free electron heat conduction mechanisms operate. At the same time, the heated material cools in the air through the surface. It is associated with convection and heat radiation mechanisms.

The dependence of the thermal conductivity $k$, and the specific heat capacity $C_{p}$ on temperature for C45 steel have been studied in [4]. By approximating the experimental data given in this work, the functions of temperature dependence of these parameters are obtained (see Fig.1, Fig.2):

$$
\begin{gathered}
k=2 \cdot 10^{-8} \cdot T^{3}-4 \cdot 10^{-5} \cdot T^{2}-0.0045 \cdot T+54 \\
C_{p}=50+450 \cdot \exp \left[-\left[\frac{T-980}{50}\right]^{2}\right]+20 \cdot T^{0.53}-0.0021 \cdot T^{1.66} .
\end{gathered}
$$

Expressions (2) and (3) are valid from $20^{\circ} \mathrm{C}$ to the melting point of steel. The calculations assume that the density does not change with temperature $-\rho=7870 \mathrm{~kg} \cdot \mathrm{m}^{-3}$. Similar experimental relationships for $k=k(T)$ and $C_{p}=C_{p}(T)$ for steel AISI 4340 have also been received in [2].

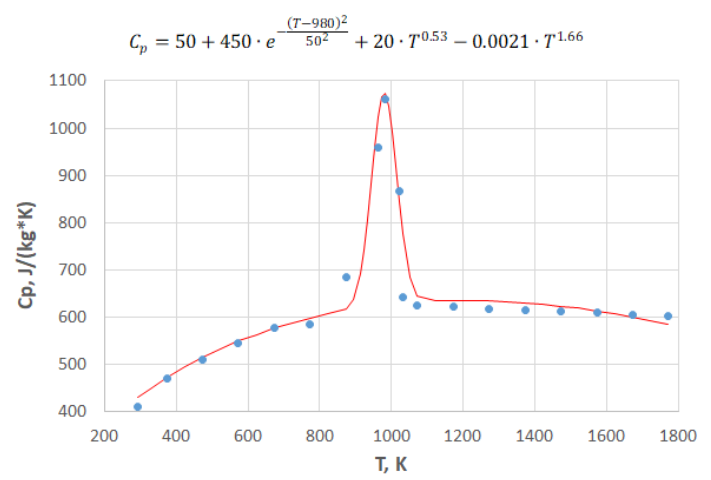

Fig. 1. C45 steel specific heat capacity dependent on temperature: experimental data [4] and approximation

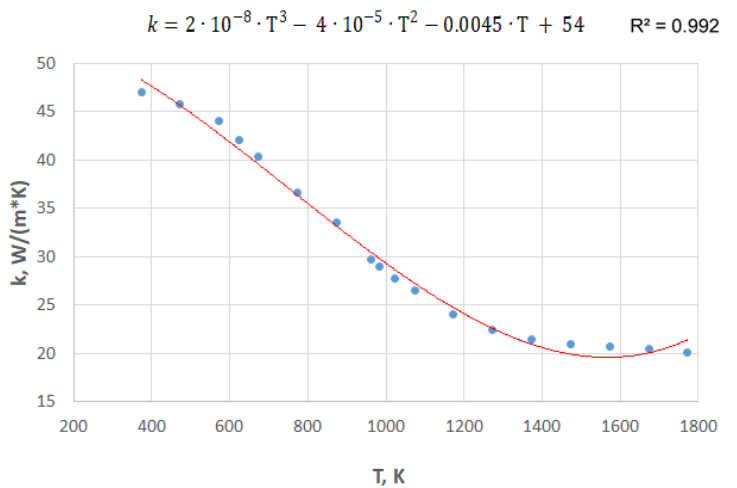

Fig. 2. C45 steel thermal conductivity dependent on temperature: experimental data [4] and approximation

Authors of works [10; 11] give a phase equilibrium diagram of $\mathrm{C} 45$ steel; which shows that the two-phase (ferrite + austenite) region exists in the temperature range $A_{1}=723$ to $A_{3}=765{ }^{\circ} \mathrm{C}$. Comparison of these data with the temperature dependence of the heat capacity investigated by [4] (where the specific heat capacity reaches a maximum in the temperature range of $600-760{ }^{\circ} \mathrm{C}$, see Fig. 1) lets conclude that the increase in heat capacity is due to phase transition (ferrite conversion to austenite), which needs to use extra heat. [10] studied that for $\mathrm{C} 45$ steel at $850{ }^{\circ} \mathrm{C}$ all ferrite is completely converted to fully austenitic equilibrium state. This temperature value is within the range of $820-860^{\circ} \mathrm{C}$ [6] for the quenching temperature of $\mathrm{C} 45$ steel (water or oil quenching as per standard). If the temperature is above $860{ }^{\circ} \mathrm{C}$, large austenitic grains may be formed, which will impair the 
mechanical properties of the material after cooling. This means that $\mathrm{C} 45$ steel should be heated to 820 $860{ }^{\circ} \mathrm{C}$ during laser annealing and cooled at a rate $>100 \mathrm{~K} \cdot \mathrm{s}^{-1}$ to martensite start temperature $M_{s}=315^{\circ} \mathrm{C}[11 ; 12]$. These temperatures should also guide for FEM calculations in determining the laser power, spot size, scan speed and the number of scans required for hardening in given depth.

Laser radiation energy is fed to the $\mathrm{C} 45$ steel through the surface of the spot. We consider the case where the spot has an elliptical shape and the energy in the spot has a Gaussian distribution. Then the heat load $\left(\mathrm{W} \cdot \mathrm{m}^{-2}\right)$ is:

$$
Q(x, y)=\frac{P \cdot\left(1-R_{c}\right)}{\pi \sigma_{x} \sigma_{y}} \cdot \exp \left[-\frac{\left(x-x_{0}\right)^{2}}{2 \sigma_{x}^{2}}-\frac{\left(y-y_{0}\right)^{2}}{2 \sigma_{y}^{2}}\right],
$$

where $P$ - total power input, $\mathrm{W}$;

$\sigma_{x}, \sigma_{y}-$ laser beam spot ellipse semi-axis, m;

$\pi \sigma_{x} \sigma_{y}-$ spot area, $\mathrm{m}^{2}$

$\exp \left[-\frac{\left(x-x_{0}\right)^{2}}{2 \sigma_{x}^{2}}-\frac{\left(y-y_{0}\right)^{2}}{2 \sigma_{y}^{2}}\right]-2 \mathrm{D}$ Gaussian distribution in coordinate xy-plane;

$R c$ - reflection coefficient.

The reflection coefficient $R c$ is determined by the composition of the steel, surface condition (roughness, the presence of oxide/corrosion film), temperature and wavelength of the laser radiation.

The reflection coefficient dependence on temperature is related to the chemical reaction (e.g. oxidation) at raised temperature on the steel surface. It was experimentally determined that steel C45 samples used in the research had a reflection coefficient at $20^{\circ} \mathrm{C}$ temperature for visible and near IR radiation $R_{0}=0.96$. In [13] it is shown that for C45 steel the reflection coefficient at $20^{\circ} \mathrm{C}$ is $R_{0}=0.65$. The difference in the experimental data can be explained by the different surface conditions of the materials. Irradiation of steel with laser radiation changes its surface condition and reduces the reflection coefficient. In this calculation it is assumed that

$$
R_{c}=R_{0} \cdot \exp [-\alpha \cdot(T-293)] .
$$

Here $R_{0}=0.9 ; \mathrm{a}=0.00055 \mathrm{~K}^{-1}$. To reduce the reflection coefficient, the steel surface can be covered with a graphite film; in this case, the surface absorptivity is about $60 \%\left(\mathrm{R}_{\mathrm{c}} \approx 0.4\right)$ [1]. The reflection coefficient also depends on the angle of incidence of the laser beam; for steel C45 with graphite spray-coating at $0^{\circ}$ absorptivity is $80 \%\left(R_{c}=0.2\right)$ [9].

The design model also takes into account cooling of the sample in air due to convection and radiation. The heat flux density $(\mathrm{W} \cdot \mathrm{m}-2)$ that the body gives back by convection

$$
q_{c}=h \cdot\left(T_{e x t}-T\right),
$$

where $h$-heat transfer coefficient, $\mathrm{W} \cdot \mathrm{m}^{-2} \cdot \mathrm{K}^{-1}$;

$T_{\text {ext }}$ - ambient air temperature, $T_{\mathrm{ext}}=20^{\circ} \mathrm{C}$;

$T$ - body surface temperature at a given location.

For the upper surface $h=10 \mathrm{~W} \cdot \mathrm{m}^{-2} \cdot \mathrm{K}^{-1}$, for side surfaces $h=7.69 \mathrm{~W} \cdot \mathrm{m}^{-2} \cdot \mathrm{K}^{-1}$, for the lower surface $h=5.88 \mathrm{~W} \cdot \mathrm{m}^{-2} \cdot \mathrm{K}^{-1}$. Calculation of the heat transfer coefficient $h$ for a rotating heating cylinder is shown in [2]. Heat flux density $\left(\mathrm{W} \cdot \mathrm{m}^{-2}\right)$ emitted by the body through radiation:

$$
q_{r}=\varepsilon \cdot \sigma \cdot\left(T_{e x t}^{4}-T^{4}\right),
$$

where $\sigma$-Stefan-Boltzmann constant, $\mathrm{W} \cdot \mathrm{m}^{-2} \mathrm{~K}^{-4}$;

$$
\varepsilon \text { - emissivity; } \varepsilon=1-R_{c} \text {. }
$$

\section{Results and discussion}

According to [6], the hardness of C45 steel after quenching should be in depth $1 \mathrm{~mm}$ 55-62HRC, $2 \mathrm{~mm}$ 51-61HRC, $3 \mathrm{~mm}$ 37-61HRC, $4 \mathrm{~mm}$ 30-60HRC. It was experimentally established that the best hardening results (if the number of scans $=1$ ) were obtained with the following parameters: laser power $900 \mathrm{~W}$, spot diameter $5 \mathrm{~mm}$, scanning speed $3 \mathrm{~mm} \cdot \mathrm{s}^{-1}$. 


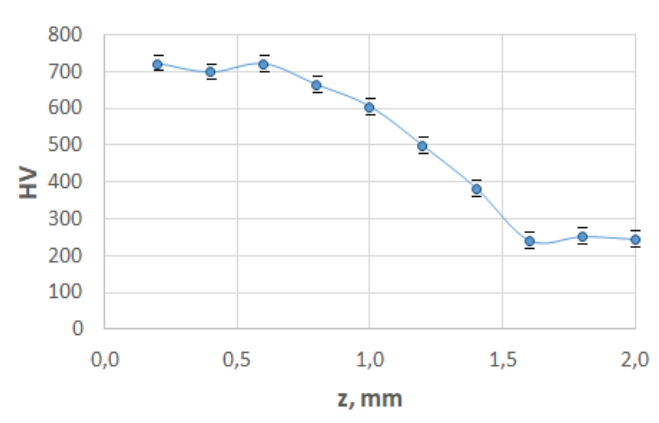

Fig. 3. Depth of hardening

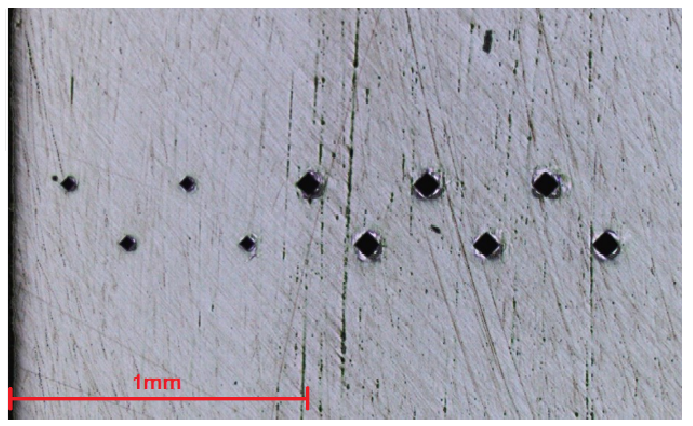

Fig. 4. Indenter prints after steel hardening

After hardening, the hardness of the cross section of the part is measured to determine the thickness of the hardened layer. Fig. 3 shows the change in hardness (HV) at different depths $z$ (on the surface of the part $z=0$ ). Fig. 4 shows the prints of the hardness tester in the cross section of steel; on the left is the surface of the part. The boundary between the hardened and non-hardened area is visually visible. The left side of the image hardened (smaller prints); right side- not hardened (larger dents).

The metallographic structure of the samples also indicates the existence of the hardened layer. In Fig. 5 the martensitic needle-like structure is visible in the hardened layer. Fig. 6 shows the boundary between the hardened (structure after laser treatment; left side of the image) and the unhardened layer (corresponds to the structure of the material before laser treatment, right side). A fragment of part used in the laser tempering tests is shown in Fig. 7.

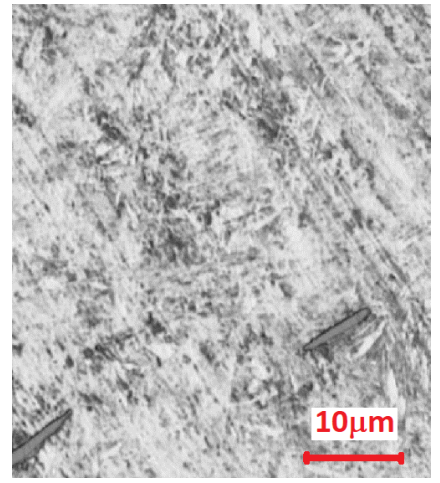

Fig. 5. Martensit structure in the laser hardened layer of C45 steel

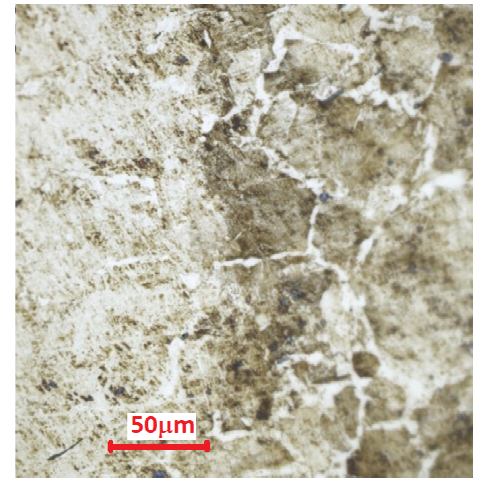

Fig. 6. Boundary between laser hardened and unhardened layers of C45 steel

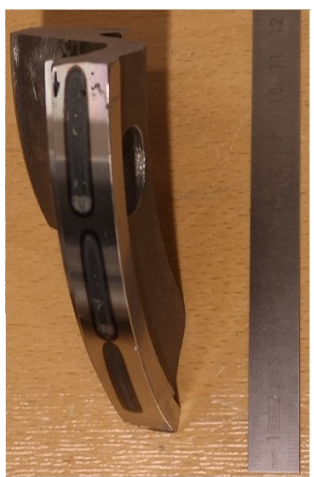

Fig. 7. Fragment of a steel

C45 part with a laser track on the surface

The temperature field calculated by COMSOL is given in Fig. 8 and Fig.9 for two different C45 steel parts for time moment $5 \mathrm{~s}$ since laser processing start. The laser beam (of $900 \mathrm{~W}$ power) moves $30 \mathrm{~mm}$ along the slit line (in $\mathrm{x}$-axis direction) with the speed of $3 \mathrm{~mm} \cdot \mathrm{s}^{-1}$; total laser processing time is $10 \mathrm{~s}$. The center of the spot at time moment $5.0 \mathrm{~s}$ is situated above the vertical red line. The maximum temperature corresponds to a surface point which center of the spot passed $0.6 \mathrm{~s}$ earlier.

The temperature on the surface must not exceed the temperature of the austenitic solidus curve (for steel C45 it is about $1400{ }^{\circ} \mathrm{C} \mathrm{[10]),} \mathrm{otherwise} \mathrm{the} \mathrm{liquid} \mathrm{phase} \mathrm{will} \mathrm{occur} \mathrm{and} \mathrm{the} \mathrm{geometry} \mathrm{of} \mathrm{the}$ part will be damaged. In addition, the liquid phase of steel releases metal vapours (cadmium, nickel, manganese, chromium) that are hazardous to human health into the environment, as is the case with laser cutting or laser welding, and special protection measures are required [14]. It is seen from Fig.89 that the liquid phase does not occur at the specified laser tempering parameters, because the maximum surface temperature does not exceed $1100^{\circ} \mathrm{C}$. To reduce the likelihood of the liquid phase occurring, the scan speed and number of passes should be increased. In this case, the laser beam is located at a specific place for a shorter period of time and cannot heat the surface of the part to the temperature of the liquid phase. As a result, the entire layer to be annealed can achieve a more uniform temperature. These conclusions follow from work [3] investigating the quality improvement of the steel laser cutting process. In [15] it has been found that shifting the focus of the laser beam to the inside of the material can significantly increase the weld depth at the same scanning speed. This means 
that defocusing can also change the thickness of the hardening layer. To model the laser hardening process by defocusing, the diameter of the spot can be changed at constant power.

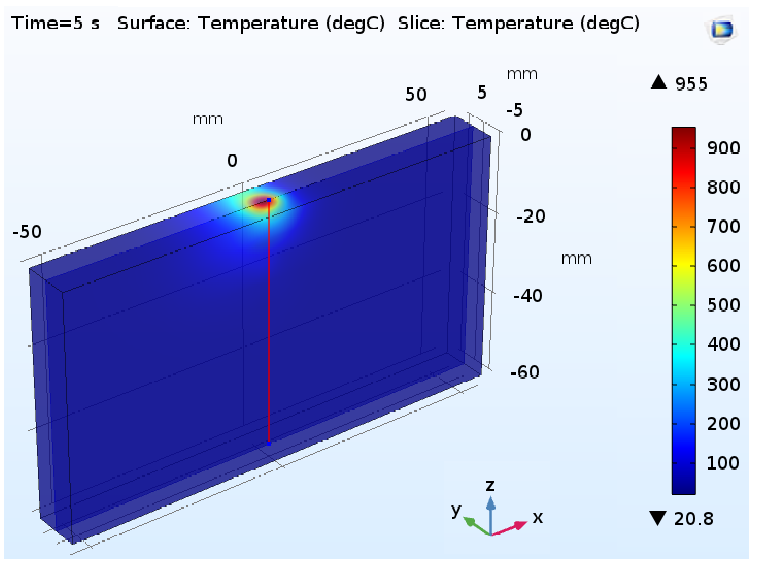

Fig. 8. Temperature field for the part with dimensions 100x10x60 mm at a time of $5 \mathrm{~s}$
Time $=5$ s Surface: Temperature $(\operatorname{deg} C)$ Slice: Temperature $(\operatorname{deg} C)$

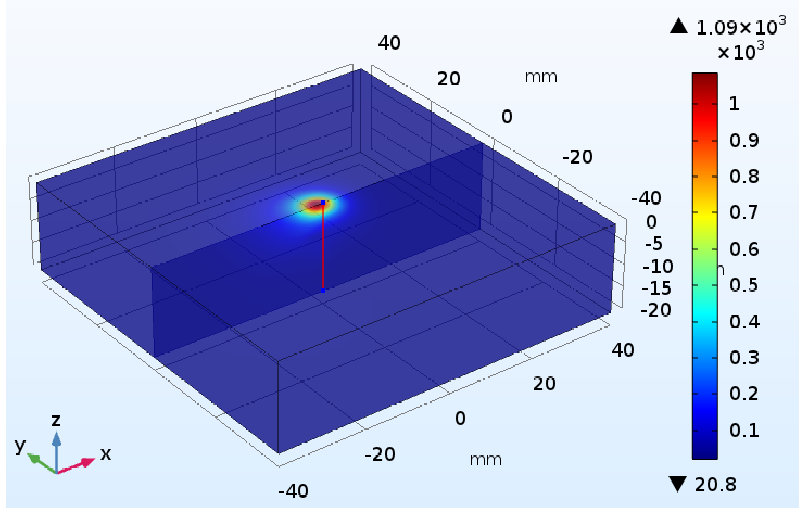

Fig. 9. Temperature field for the part with dimensions 80x80x20 $\mathrm{mm}$ in $5 \mathrm{~s}$

Fig.10 shows the temperature of the steel for a part with dimensions $100 \times 10 \times 60 \mathrm{~mm}$ at various depths $z$ (on the red vertical line in Fig.8) in time interval from $5.6 \mathrm{~s}$ to $9.6 \mathrm{~s}$ with steps of $0.2 \mathrm{~s}$. At a time of $5.6 \mathrm{~s}$ the temperature on the red line in Fig. 8 has reached its maximum. The upper blue curve in Fig. 10 corresponds to this time moment. The green curve situated lower corresponds to a time of $5.8 \mathrm{~s}$; the next red curve down corresponds to $6.0 \mathrm{~s}$ and so on. Analogically Fig. 11 shows the temperature of the steel for a part with dimensions $80 \times 80 \times 20 \mathrm{~mm}$ at various depths $z$ (on the red vertical line in Fig.9) in time interval from $5.6 \mathrm{~s}$ to $8.0 \mathrm{~s}$ with steps of $0.2 \mathrm{~s}$.

The surface temperature of $1000{ }^{\circ} \mathrm{C}$ cannot produce large austenitic grains, because of its heating from $20^{\circ} \mathrm{C}$ to $1000{ }^{\circ} \mathrm{C}$ lasts $1.7 \mathrm{~s}$ (laser scan speed $3 \mathrm{~mm} \cdot \mathrm{s}^{-1}$, spot diameter $5 \mathrm{~mm}$ ), followed immediately by cooling to $700^{\circ} \mathrm{C}$ in $1.2 \mathrm{~s}$ (see Fig. 10).
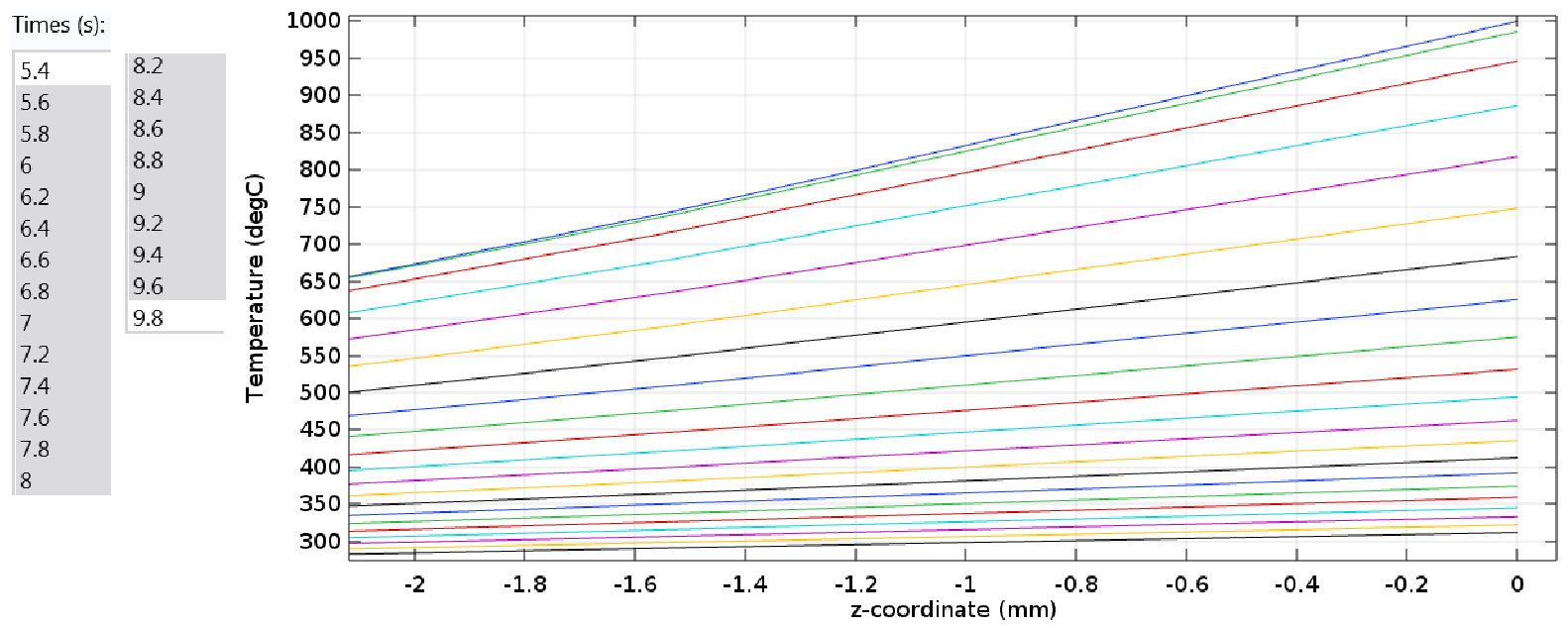

Fig. 10. Temperature of steel at various depths $z$ (on surface $z=0$ ) and at different time points from 5.6 to $9.6 \mathrm{~s}$ for the part with dimensions $100 \times 10 \times 60 \mathrm{~mm}$

The graphs in Fig. 10 and Fig.11 allow determining the thickness of the hardened layer. To harden steel C45 it must be heated to a temperature of $T_{1}=820-860{ }^{\circ} \mathrm{C}$ [6]. The maximum depth, at which the steel is heated up to these temperatures, is, respectively, 1.1- $0.9 \mathrm{~mm}$ (see Fig. 10, blue upper curve). The steel C45 should then be cooled to martensitic start temperature $M_{s}=315^{\circ} \mathrm{C}$ at a cooling rate $C R$ that exceeds the critical cooling rate $C R_{c}=100 \mathrm{~K} \cdot \mathrm{s}^{-1}[11]$. The cooling rate is:

$$
C R=\frac{T_{1}-M_{s}}{t_{M s}-t_{1}},
$$

where $t_{1}$ - time moment corresponding to temperatures $T_{1}, \mathrm{~s}$; 
$t_{M s}$ - time moment corresponding to temperatures $M s$.

In this case, at the depths of $\mathrm{z}=1.1 \mathrm{~mm}$ and $\mathrm{z}=0.9 \mathrm{~mm}$, the cooling rates are:

$$
C R_{z=1.1 \mathrm{~mm}}=\frac{820-315}{9.4-5.6}=133 \mathrm{Ks}^{-1}, C R_{z=0.9 \mathrm{~mm}}=\frac{860-315}{9.5-5.6}=140 \mathrm{Ks}^{-1} \text {. }
$$

Both of these cooling rates exceed the critical $C R_{c}$. This means that the boundary separating the hardened and non-hardened layer is at a depth of $0.9-1.1 \mathrm{~mm}$. This is evidenced by the hardness reduction of the layer, which is located at a depth of $0.9 \mathrm{~mm}$ to $1.6 \mathrm{~mm}$. (see Figure 3,4 ).

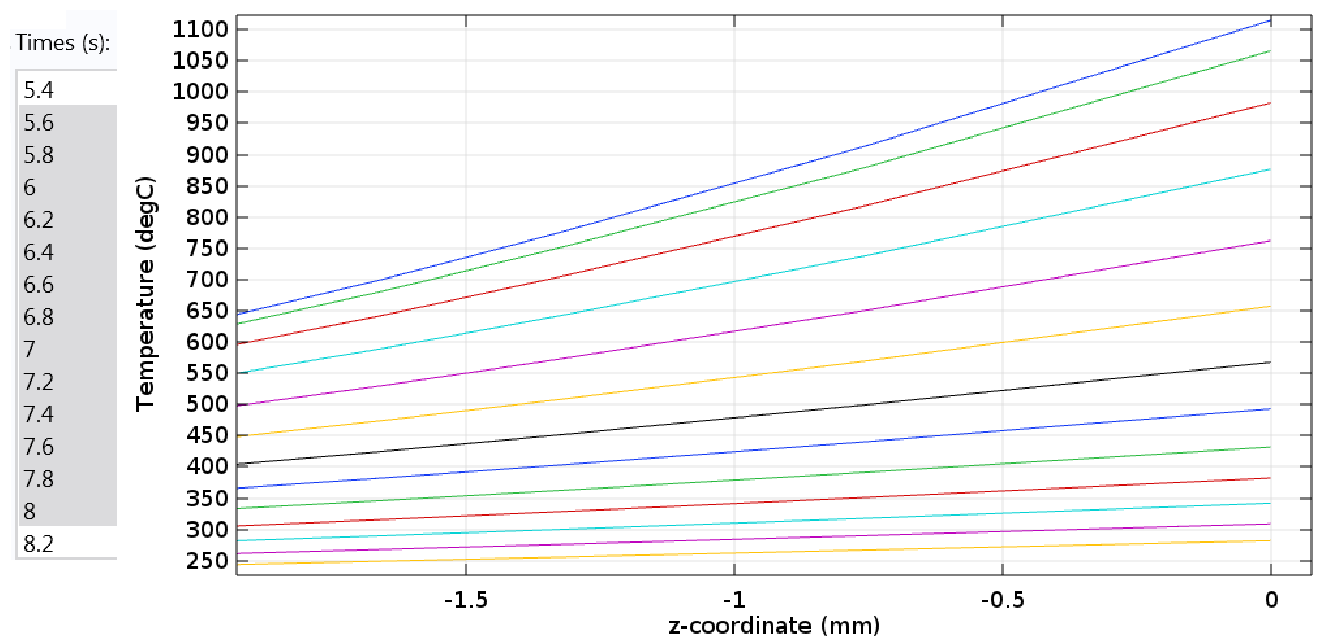

Fig. 11. Temperature of steel at various depths $z$ (on surface $z=0)$ and at different time points from 5.6 to $8.0 \mathrm{~s}$ for the part with dimensions $80 \times 80 \times 20 \mathrm{~mm}$

The temperature field, tempering depth, and the cooling rate (under the same conditions) also depend on the part shape, size, laser beam track length, and location on the part surface (compare Figs. 8, 9 and Fig. 10, 11). For example, the hardening depth for part in Fig 9 is 1.2-1.0 mm (see Fig. 11, blue upper curve) and a cooling rate of $253-273 \mathrm{~K} \cdot \mathrm{s}^{-1}$ respectively.

This method may be used to determine the material reflectivity factor dependence on temperature $R_{c}=R_{c}(T)$, if for a part of specified size and shape the thickness of the hardened layer is experimentally determined and also $k=k(T), C_{p}=C_{p}(T)$,laser power, scanning speed and spot diameter are known. For this purpose it is necessary to create a 3D model of the part and with Comsol software perform several calculations of the temperature field, each time changing the parameters of the function $R_{c}=R_{c}(T)$, for example, $R_{0}$ and $a$ in formula (5). The case, where the calculated and experimentally determined thicknesses of the hardened layer coincide, corresponds to the function $R_{c}=R_{c}(T)$. In this work the function in formula (5) is also obtained this way.

A comparison of the results obtained in this work (with a diode laser) with the results obtained in [1] (with an Nd: Yag laser) is shown in Table 2. Optimal parameters are those that provide the maximum depth of the hardened layer $(>500 \mathrm{HV})$ and the lowest maximal surface temperature.

Table 2

Comparison of $\mathrm{C45}$ steel laser hardening results

\begin{tabular}{|c|c|c|c|}
\hline \multicolumn{2}{|l|}{ Laser } & Diode laser, $808 \mathrm{~nm}, 940 \mathrm{~nm}$ & Nd: Yag laser, $1064 \mathrm{~nm}$ \\
\hline \multicolumn{2}{|l|}{ Material } & $\mathrm{C} 45,240 \mathrm{HV}$ & $\mathrm{C} 45,200 \mathrm{HV}$ \\
\hline \multicolumn{2}{|c|}{ Surface coating } & Uncoated & Graphite coating \\
\hline \multicolumn{2}{|c|}{ Scanning length, mm } & 30 & 30 \\
\hline \multicolumn{2}{|c|}{ Sample thickness, $\mathbf{m m}$} & 10 & 8 \\
\hline \multirow{3}{*}{$\begin{array}{l}\text { Optimal } \\
\text { parameters }\end{array}$} & Laser power, $\mathbf{W}$ & 900 & 450 \\
\hline & Scanning spied, $\mathbf{m m} \cdot \mathbf{s}^{-1}$ & 3 & 1.7 \\
\hline & Spot diameter, $\mathbf{m m}$ & 5 & 2.73 \\
\hline \multicolumn{2}{|c|}{ Maximal surface temperature, ${ }^{\circ} \mathrm{C}$} & 1100 & 1020 \\
\hline \multicolumn{2}{|c|}{ Depth of hardened $(>500 \mathrm{HV})$ layer, $\mathrm{mm}$} & 1.2 & 0.3 \\
\hline \multicolumn{2}{|c|}{ Surface hardness, HV } & 720 & 700 \\
\hline
\end{tabular}




\section{Conclusions}

1. The method for optimization of the laser annealing process of steel C45 using FEM is developed, which reduces the number of real annealing experiments by replacing them with numerical calculations. The method allows to predict the thickness of the hardened layer on a particular part depending on the laser power, length and location of the laser beam track on the surface of the part, the scanning speed and the spot size. Calculations take into account the dependence of the thermal conductivity, specific heat capacity and the reflection coefficient on temperature. The method was experimentally tested on parts with a flat hardening surface (radius of curvature is many times larger than the spot diameter).

2. The method is based on the non-stationary heat conduction equation; it is suitable for C45 steel parts of any shape, provided that the heat transfer coefficients on the surfaces are known, the laser beam track is completely placed on the flat surface of the hardened area of a part, the spot diameter does not change during laser treatment and the part is large enough to provide the required cooling rate. The method can also be used for other steel grades, if the temperature dependence of the thermal conductivity, specific heat capacity and the reflection coefficient of these materials, as well as the quenching temperature, martensitic start temperature and the critical cooling rate are known.

3. The method allows calculating the change in the temperature of the surface to be annealing during the laser treatment, to calculate the maximum temperature and, depending on it, to predict whether the geometry of the part will not be damaged by melting. In the future, it is intended to develop this method in order to use it for calculation of the mechanical stresses caused by uneven heating and cooling of the part and, on this basis, to predict the formation of cracks in the hardened surface.

4. The developed methodology can be successfully used for hardening of the quickly wearing parts and elements of agricultural machines, such as the ploughshare during ploughing of heavy clay soils.

\section{References}

[1] Bouquet J., Van Camp D., Vanhove H. etc. Development of a flexible laser hardening \& machining center and proof of concept on C-45 steel. Physics Procedia, vol. 56, 2014, pp. 10831093.

[2] Fakir R., Barka N., Brousseau J. Case study of laser hardening process applied to 4340 steel cylindrical specimens using simulation and experimental validation. Case Studies in Thermal Engineering, vol 11, 2018, pp. 15-25.

[3] Ullmann F., Loeschner U., Hartwig L. etc. Highspeed laser ablation cutting of metal. Proc. of SPIE - The International Society for Optical Engineering, vol. 8603:11, 2013, pp.1-10.

[4] Lazic, V.N., Ivanovic I.B., Sedmak A.S. etc. Numerical Analysis of Temperature Field During Hardfacing Process and Comparison with Experimental Results. Thermal Science, vol. 18, 2014, pp. 113-120.

[5] Narica P., Lazov L., Teilans A. etc. Method for color laser marking process optimization with the use of genetic algorithms. Proc. of the 11th International Scientific and Practical Conference "Environment. Technology. Resources", vol. 2, June 15-17, 2017, Rezekne, Latvia, pp. 101-105.

[6] DIN EN 10083-2: 2006-10 Steels for quenching and tempering. Part 2: Technical delivery conditions for non alloy steels.

[7] Heat Transfer Module User's Guide, 1998-2018 COMSOL, Version: COMSOL 5.4.

[8] Majchrzak E., Turchan Ł. Boundary element method for 3D Fourier-Kirchhoff heat transfer equation. Scientific Research of the Institute of Mathematics and Computer Science, vol. 9, 2010, pp. 121-130.

[9] Bouquet J., Van Camp D., Malek O. etc. Aiming for improved lifetime of die and mold components through an integrated laser hardening operation, combining machining and a selective heat treatment in one setup. Procedia CIRP, vol. 46, 2016, pp. 541-544.

[10] Wilzer J., Lüdtke F., Weber S. etc. The influence of heat treatment and resulting microstructures on the thermophysical properties of martensitic steels. J Mater Sci, vol. 48, 2013, pp. 8483-8492. 
[11] Stodolny J., Gołaszewski A., Łotarewicz A. Fragmentation Rate of Cementite Lamellas in Nanopearlite. JOM, vol. 71, No. 9, 2019, pp. 3298-3304.

[12] Colas R., Totten G. E. Encyclopedia of Iron, Steel and Their Alloys. Volume II. $1^{\text {st }}$ edition. London, New York: CRC Press, 2016. pp. 751-1508.

[13] Tsarkova O. G. Optical and thermal properties of metals, ceramics, and CVD diamond films upon high-temperature laser heating. Physics of Wave Phenomena, vol. 15, 2007, pp. 12-45.

[14] Narica P., Martinsone I., Reducing Risk Factors in the Workplace of the Laser System Operator. Proceedings of the 12th International Scientific and Practical Conference "Environment. Technology. Resources", vol. 3, June 20-22, 2019, Rezekne, Latvia, pp. 184-188.

[15] Drechsel J., Schille J., Hanelt K. etc. Laser welding of AlSi12 and S355 with a $10 \mathrm{~kW}$ single mode fiber laser. Journal of Laser Applications 31(2): 022415, 2019. 